\title{
Design and Off-Design Performance Evaluation of Heat Exchanger in an Offshore Process Configuration
}

\author{
Sidum Adumene1, Thaddeus C. Nwaoha², Garrick P. Ombor ${ }^{2}$, Joshua T. Abam² \\ ${ }^{1}$ Department of Marine Engineering, Rivers State University of Science and Technology, Port Harcourt, Nigeria \\ ${ }^{2}$ Department of Marine Engineering, Federal University of Petroleum Resources, Effurun, Nigeria \\ Email: sidum.adumene@ust.edu.ng, Thaddeus_cn@yahoo.co.uk
}

Received 18 May 2016; accepted 14 June 2016; published 17 June 2016

Copyright (C) 2016 by authors and OALib.

This work is licensed under the Creative Commons Attribution International License (CC BY). http://creativecommons.org/licenses/by/4.0/

(c) (i) Open Access

\section{Abstract}

This research evaluates the thermal performance of an industrial heat exchanger for process in the offshore industry. Steady state monitoring and performance data were collected from 3-E-401 heat exchanger in an offshore environment. Design and off-design evaluation was carried out using capacity ratio, effectiveness, Log Mean Temperature Difference (LMTD), heat duty, and overall heat transfer coefficient as performance indicators. Three scenarios were presented and Hysys ${ }^{\circledR}$ V8.7 software was used to model the process. The results showed that the best thermal performance of the heat exchanger in terms of capacity ratio, effectiveness, heat duty, LMTD, and overall heat transfer coefficient is $94 \%, 85.5 \%, 88 \%, 88.7 \%$ and $71 \%$ respectively, of the design values. This best performance was reached at $9.9 \%$ fouling and heat loss reduction in the heat exchange process. An increase in fouling and heat loss gradually reduced the thermal performance of the heat exchanger. Therefore a proactive maintenance action and condition monitoring in every eight weeks is required to sustain and improve the performance as evaluated.

\section{Keywords}

Heat Exchanger, Effectiveness, Heat Duty, Fouling Factor, Performance, LMTD

Subject Areas: Industrial Engineering

\section{Introduction}

A heat exchanger transfers the energy from a hot fluid to a cold fluid; with maximum rate and minimum investment and running cost [1]. It is a device in which energy is transferred from one fluid to another across a solid surface. It is applied where high temperature and pressure demands are significant and can be employed for a

How to cite this paper: Adumene, S., Nwaoha, T.C., Ombor, G.P. and Abam, J.T. (2016) Design and Off-Design Performance Evaluation of Heat Exchanger in an Offshore Process Configuration. Open Access Library Journal, 3: e2748.

http://dx.doi.org/10.4236/oalib.1102748 
process requiring large quantities of fluid to be heated or cooled. Due to the design of the shell and tube heat exchanger, it offers a large heat transfer area and provides high heat transfer efficiency in comparison with others [2]. Most materials are exposed to adverse environmental condition while in service. This results in the deterioration of the surface, mechanical properties, physical properties, and appearance of the materials [3]. Deterioration processes for metals and alloys are called corrosion. Their deterioration occurs at elevated temperature. When a material is under stress, cracks are formed. These cracks propagate through the material as the stress is increased and the material fails by breaking into two or more parts. Condition monitoring performance evaluation is then the process of monitoring operating parameters in equipment such that any significant change is an indication of a developed failure [4]. It is typically more cost effective than allowing the equipment to fail. According to [1], the temperature of each fluid changes as it passes through the exchangers, and hence the temperature of the dividing wall between the fluid also changes along the length of the exchanger in which a liquid or gas is required to be either cooled or heated.

The most important heat exchanger type is the recuperator in which the flowing fluids exchanging heat are on either side of a dividing wall [1]. The second type is a regenerator in which the hot and cold fluids pass alternatively through a space containing a matrix of material that provides alternative means for heat flow. The third type is the evaporative type in which a liquid is cooled evaporatively and continuously in the same space as the coolant. It was evident in [5] that in a direct compact or open heat exchanger, the exchange of heat takes place by direct mixing of hot and cold fluids and transfer of heat and mass takes place simultaneously. The use of such units is done under conditions where mixing of two fluids is either harmless or desirable such as cooling towers, jet condensers and direct contact feed heater. In the indirect contact, heat is transfered between two fluids by transmission through walls which separates the two fluids. In parallel flow heat exchanger, the two fluid streams (hot and cold) travel in the same direction. While in counter flow, the two fluids flow in opposite direction. This flow pattern gives maximum rate of heat transfer for a given surface area, although fouling is a limiting factor in this case. Hence such heat exchangers are most favoured for heating and cooling of fluid [5].

In the work of [6], it was reported that due to fouling the overall heat transfer coefficient of three co-current heat exchanger in a polyethylene plant show $51.60 \%, 80.71 \%$ and $57.73 \%$ less than the design value respectively. An experimental determination of fouling factor on plate heat exchangers was presented in [7]. The work describes the influence of water velocity on fouling factor in plate heat exchanger for four district heating substation. It was observed that the heat duty reduced greatly due to fouling. Also [8] used augmentation techniques to enhance the heat transfer in the annulus of the heat exchanger design systems. These techniques greatly improved the performance of the heat exchanger. Heat transfer enhancements devices are commonly employed to improve the performance of an existing heat exchanger or to reduce the size and cost of a proposed heat exchanger.

This paper presents a design and off-design thermal performance evaluation based on steady state monitoring and process simulation. The data are used to evaluate the state of performance based on key performance indicators and to predict the best performance index from the three scenarios. The comparative analysis was also taken into consideration. This enables a maintenance predicted period to sustain the thermal performance of the system in order to eliminate fouling and heat losses.

\subsection{Performance Mitigating Factors}

\section{a. Fouling or Scaling}

Fouling occurs when a fluid goes through the heat exchanger and the impurities in the fluid precipitate onto the surface of the tubes [5]. The precipitation of these impurities is caused by frequent use of the heat exchanger, velocity reduction of fluids flow through the heat exchanger and over-sizing the heat exchanger. The effects of fouling are evident more in the cold tubes of the exchanger that in the hot tubes. This is because impurities are less likely to dissolve in a cold fluid, since for most substances solubility increases as temperature increase. Although hard wall is an exception, the reverse is the case. Fouling also reduces the cross sectional area for heat to be transferred and causes an increase in the resistance to heat transfer across the heat exchanger. The thermal conductivity is lowered by fouling. If the overall heat transfers coefficient and efficiency of the heat transfer is reduced, there will be an increase in pumping and maintenance costs.

\section{Choking of tubes}

Gas flow or fluid flow can be choked at exit of the tube. This may occur at the transient condition where the high pressure bubble of gas or fluid vortex is generated with a maximum momentum which forced the liquid 
from the low pressure (LP) side. This process occurs at maximum pressure in the LP side of the heat exchanger and is characterized by a pseudo-steady-state process that depends on the flow resistance.

\section{b. Low tube velocity}

For most fluids in most applications, a lower tube velocity means a lower inside heat transfer coefficient, therefore the heat transfer is less effective, so thermal designers will maintain performance by keeping the velocity as high as the tube material and pressure drop is not compromised. Other performance mitigating factors are excessive transfer rates, lack of effective control system, unequal heating.

\subsection{Heat Exchanger Condition Monitoring}

The growing technical complexity of engineering system such as heat system, together with the intense public need over high safety and performance of such systems. It is therefore necessary to enhance an effective, safety and workable heat exchange system that will meet the need of the industry. One pervasive cost that drags down productivity and performance is the unplanned equipment and manufacturing process downtime [9]. When failure has already commenced, condition monitoring system can only measure the deterioration of the condition. Proper maintenance and operating practices can significantly affect the level of performance degradation and thus time between repairs or overhaul of the heat exchanger. Proactive condition monitoring will allow the heat exchanger operator to make intelligent service decision based on the actual condition of the heat exchanger rather than on a fixed and calendar based maintenance interval. This type of condition monitoring will further reduce the heat exchanger degradation and deterioration. It is typically more cost effective than allowing the equipment to fail [4]. Serviceable machinery includes rotating equipment and stationary plant such as boilers and heat exchangers.

The use of condition monitoring allows maintenance or other action to be taken to avoid the consequence of failure, before the failure occurs. Predictive maintenance does not only or necessarily predict failure, it also helps to predict the time of failure. Once machinery such as a heat exchanger is put to use, degradation and deterioration start. However, it is typically much more cost effective to measure the deterioration than allowing the machinery to fail [10]. The aim of this is to generate some proactive models to enhance the performance evaluation of a shell and tube heat exchanger. The method of monitoring used for heat exchangers is performance trend monitoring. Elementary trends are demonstrated by such simple methods as relating the pressure drop and through-flow in a heat exchanger. The buildup of deposits in the flow lines will be revealed by increase in pressure-drop needed to maintain a certain rate or through-put. It was explained, that temperature difference on both inlet and outlet of both hot and cold section can indicate the thickening of films and reduction in heat transfer coefficients. It was further added that the presence of continuous monitoring does not eliminate the need for periodic monitoring. Continuous monitoring systems warn the operator about imminent problems. The continuous monitoring is thus required for heat exchangers, and adopted in this research.

Integrity inspection of plates and tubular heat-exchanger can be tested in-situ by the conductivity of helium gas method. These methods confirm the integrity of the plates or tubes to prevent any cross contamination and the condition of the gaskets. Condition monitoring of heat exchanger tubes may be conducted through Non destructive methods such as eddy current testing [5].

\subsection{Measures for Increasing Heat Exchanger Performance}

It is evident in [11], that increasing heat exchanger performance usually means transforming more heat duty or operating the exchanger at a closer temperature approach. This can be accomplished without a dramatic increase in surface area. Sometimes increasing heat exchanger performance may not result from increases in through put or higher duties. These issues may arise simply because the exchanger is not working correctly at the present capacity [12]. He stated that the pertinent information is to diagnose the problems and possible solutions for shell and tube heat exchanger that are not working.

Several researchers include the performance optimization of heat exchangers subject to fouling by the use of high pressure water jetting and chemical cleaning technique [13]. Exergy analyses have also been used for performance evaluation of heat exchanger in which effectiveness and exergy were compared [14]. Numerical analysis of plate heat exchanger has also been applied to evaluate the performance in a co-current fluid flow configuration heat exchanger. Ref. [15] carried out the performance improvement in a concentric circular heat exchanger with external recycle under uniform wall fluxes. The study reveals a considerable improvement of heat 
transfer efficiency obtainable by inserting an impermeable tube into a laminar counter flow concentric circular heat exchanger with external recycle under uniform wall fluxes.

The performance optimization of the heat exchanger through condition monitoring takes the following into consideration:

- Determine whether the exchanger is operating correctly;

- Estimate how much pressure drop is available;

- Utilization of enhancers or intensifier such as firing, tube inserts, modified tubes or modified baffle.

\section{Materials and Methods}

\section{Theoretical Performance Formulation}

Numerical based tool and condition monitoring technique were applied for the analysis of heat exchanger in three different scenarios. Performance analysis is often closely related to energy efficiency, and therefore has long been applied for accuracy measures and studies on deterioration. With performance analysis, it is possible to calculate the optimum time for overhaul to sustain and restore regarded performance. The Modelling is a representation of physical or chemical process by a set of mathematical relationships that adequately describe the significant process behavior. Improving or understanding chemical process operation is a major objective for developing a process model. This formulation are often used for process design, safety system analyse, process control and monitoring. In predicting the performance of a heat exchanger (Figure 1), the energy formulation is adopted.

For Heat loss by the Hot Fluid

$$
Q_{h}=m_{h} C_{p h}\left(t_{h 1}-t_{h 2}\right)
$$

For Heat gain by the Cold Fluid

$$
Q_{c}=m_{c} C_{p c}\left(t_{c 1}-t_{c 2}\right)
$$

For total heat Transfer Rate

$$
Q=U A t_{m}
$$

For the Log Mean Temperature Difference (LMTD)

$$
\text { LMTD }=\frac{\Delta T_{1}-\Delta T_{2}}{\ln \left(\frac{\Delta T_{1}}{\Delta T_{2}}\right)}
$$

For fluids separated by a plane wall:

$$
t_{h 1}
$$

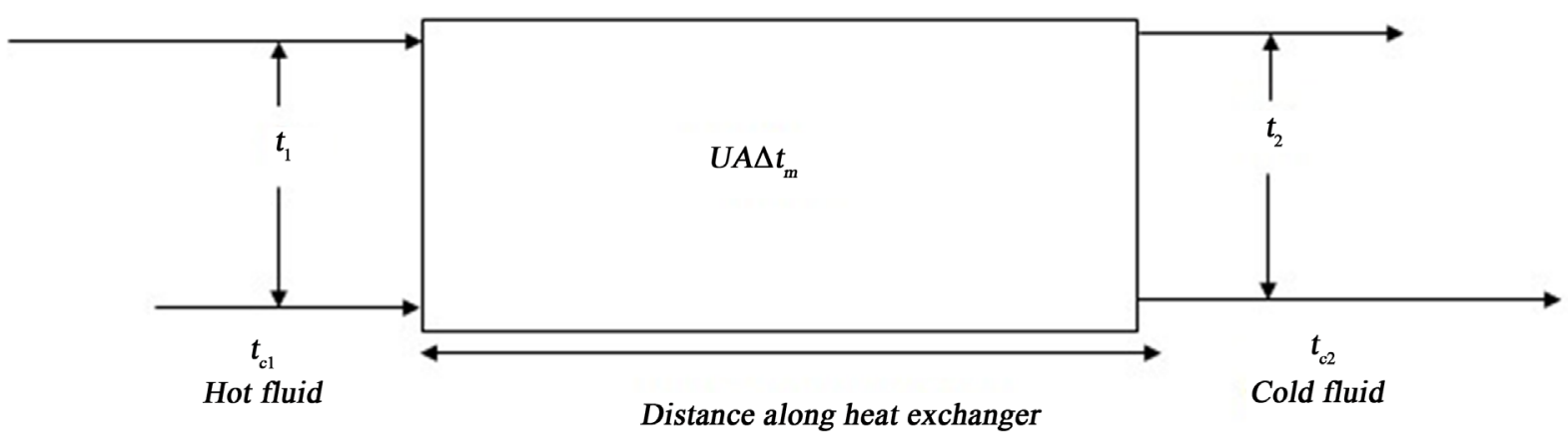


Overall Heat Transfer Coefficient

$$
U=\frac{1}{\frac{1}{h_{i}}+\frac{L}{k}+\frac{1}{h_{o}}}
$$

For fluids flowing inside and outside a tube:

Overall Heat Transfer Coefficient

$$
U=\frac{1}{\frac{1}{h_{i}}\left(\frac{r_{o}}{r_{1}}\right)+\frac{r_{i}}{k}+\frac{L}{k} \ln \left(\frac{r_{i}}{r_{o}}\right)+\frac{1}{h_{o}}}
$$

For effect of scale on heat flow:

The thermal resistance to scale formation on the inside surface (Overall Heat Transfer Coefficient $\left(R_{s i}\right)$ and outside surface $\left(R_{\text {so }}\right)$ are given by

$$
R_{s i}=\frac{1}{A_{i} h_{s i}} ; R_{s o}=\frac{1}{A_{o} h_{s o}}
$$

The fouling factor $R_{f}=\frac{1}{h_{s}} ; h_{s}=$ reciprocal of scale heat transfer coefficient

$$
R_{f}=\frac{1}{h_{s}}=\frac{1}{U_{\text {dirty }}}-\frac{1}{U_{\text {clean }}}
$$

For the Thermal Resistance /Overall heat transfer coefficient due to scale formation

$$
Q=\frac{t_{i}-t_{o}}{\frac{1}{A_{i} h_{i}}+\frac{1}{A_{i} h_{s i}}+\frac{1}{2 \pi L k} \ln \left(\frac{r_{i}}{r_{o}}\right)+\frac{1}{A_{o} h_{s o}}+\frac{1}{A_{o} h_{o}}}
$$

For Heat Exchanger Effectiveness

$$
\begin{gathered}
\varepsilon=\frac{\text { Actual heat transfer }}{\text { Maximum possible heat transfer }}=\frac{Q}{Q_{\max }} \\
Q=\varepsilon C_{\min }\left(t_{h 1}-t_{c 1}\right)
\end{gathered}
$$

For Number of Transfer units (NTU)

$$
\mathrm{NTU}=\frac{U A}{C_{\min }}
$$

For negligible fluids viscosities and pressure loss coefficient

$$
\Delta P_{t}=4 f\left(\frac{L}{d_{i}}\right)\left(\frac{h^{2}}{2 g p}\right)
$$

\section{Results and Discussion}

The results for the heat exchanger were obtained by evaluating the various inlets and outlets temperatures, pressure and flow rate. Table 1 shows the design parameters, while Tables 2-4 show the average summary of the results of the simulation at design point and off-design points respectively. Tables 5-7 show the percentage performance of the various indicators with respect to the design values.

The results from Tables 2-4 showed a progressive increase in the LMTD performance in the off-design analysis under the various considerations. The deduction in fouling effects shows an increasing trend in the offdesign analysis. The fouling factor is dependent on the cross sectional area and the heat transfer rate across the elements of the exchanger. Though, the fouling factor deviation from the design values reflected on the overall 
Table 1. Heat transfer design data.

\begin{tabular}{ccc}
\hline PARAMETER & UNITS & PLANT DATA \\
\hline Heat Duty & $\mathrm{KW}$ & 3390.32 \\
Overall Heat Transfer Coefficient (U) & $\mathrm{KW} / \mathrm{m}^{2} \mathrm{~K}$ & 0.6545 \\
Capacity Ratio & & 1.966 \\
Fouling Factor & $\mathrm{m}^{2} \mathrm{~K} / \mathrm{KW}$ & 7.5967 \\
LMTD & & 57.689 \\
\hline
\end{tabular}

Table 2. Result of design point performance simulation of heat exchanger.

\begin{tabular}{rccccccc}
\hline$\Delta \mathrm{t}_{\mathrm{h}}{ }^{\circ} \mathrm{C}$ & $\Delta \mathrm{t}_{\mathrm{c}}{ }^{\circ} \mathrm{C}$ & Capacity Ratio (CR) & Effectiveness $(\varepsilon)$ & LMTD & $\begin{array}{c}\text { Heat Transfer } \\
\text { Rate Q }(\mathrm{KW})\end{array}$ & $\mathrm{U}\left(\mathrm{kW} / \mathrm{m}^{2} \mathrm{~K}\right)$ & $\mathrm{R}_{\mathrm{f}}\left(\mathrm{m}^{2} \mathrm{~K} / \mathrm{kW}\right)$ \\
\hline 2.40 & 12.97 & 0.21 & 5.17 & 9.27 & 989 & 0.118 & 6.12 \\
4.56 & 6.76 & 0.68 & 1.49 & 15.95 & 1686 & 0.116 & 6.11 \\
2.64 & 11.72 & 0.25 & 4.31 & 4.89 & 957.4 & 0.219 & 2.17 \\
5.10 & 17.38 & 0.29 & 3.39 & 5.51 & 1830 & 0.369 & 4.30 \\
4.60 & 19.7 & 0.23 & 4.28 & 8.21 & 1648 & 0.223 & 2.08 \\
\hline
\end{tabular}

Table 3. Result of off-design performance simulation at higher temperature gradient on the hot stream.

\begin{tabular}{rcccccccc}
\hline$\Delta \mathrm{t}_{\mathrm{h}}{ }^{\circ} \mathrm{C}$ & $\Delta \mathrm{t}_{\mathrm{c}}{ }^{\circ} \mathrm{C}$ & Capacity Ratio (CR) & Effectiveness $(\varepsilon)$ & $\mathrm{LMTD}$ & $\begin{array}{r}\text { Heat Transfer } \\
\text { Rate Q }(\mathrm{KW})\end{array}$ & $\mathrm{U}\left(\mathrm{kW} / \mathrm{m}^{2} \mathrm{~K}\right)$ & $\mathrm{R}_{\mathrm{f}}\left(\mathrm{m}^{2} \mathrm{~K} / \mathrm{kW}\right)$ \\
\hline 156.8 & 7.90 & 19.88 & 0.55 & 57.59 & 4688.01 & 0.11 & 2.77 \\
76.50 & 3.30 & 25.51 & 0.62 & 43.88 & 1841.91 & 0.21 & 4.97 \\
80.90 & 2.90 & 89.89 & 0.11 & 48.11 & 1680.81 & 0.18 & 5.17 \\
84.90 & 1.50 & 56.01 & 0.18 & 57.60 & 1960.24 & 0.32 & 3.96 \\
41.70 & 2.60 & 41.71 & 0.24 & 48.52 & 1017.93 & 0.14 & 6.63 \\
\hline
\end{tabular}

Table 4. Result of off-design performance simulation at higher temperature gradient on the cold stream.

\begin{tabular}{|c|c|c|c|c|c|c|c|}
\hline$\Delta \mathrm{t}_{\mathrm{h}}{ }^{\circ} \mathrm{C}$ & $\Delta \mathrm{t}_{\mathrm{c}}{ }^{\circ} \mathrm{C}$ & Capacity Ratio (CR) & Effectiveness ( $\varepsilon$ ) & LMTD & $\begin{array}{l}\text { Heat Transfer } \\
\text { Rate Q (KW) }\end{array}$ & $\mathrm{U}\left(\mathrm{kW} / \mathrm{m}^{2} \mathrm{~K}\right)$ & $\mathrm{R}_{\mathrm{f}}\left(\mathrm{m}^{2} \mathrm{~K} / \mathrm{kW}\right)$ \\
\hline 35.44 & 294.60 & 0.12 & 8.32 & 63.21 & 5382.50 & 0.47 & 5.70 \\
\hline 37.04 & 292.53 & 0.13 & 7.91 & 77.16 & 6070.00 & 0.99 & 6.79 \\
\hline 37.62 & 298.5 & 0.13 & 7.82 & 89.24 & 6325.27 & 0.79 & 4.57 \\
\hline 10.10 & 308.70 & 0.14 & 8.47 & 66.55 & 1368.43 & 0.98 & 3.81 \\
\hline 32.00 & 314.00 & 0.11 & 9.71 & 99.90 & 1862.43 & 0.69 & 5.39 \\
\hline
\end{tabular}

Table 5. Percentage (\%) performance of the heating elements at design point: scenario one.

\begin{tabular}{cccccc}
\hline Capacity Ratio (CR) & Effectiveness $(\varepsilon)$ & LMTD & Heat Transfer Rate Q $(\mathrm{KW})$ & $\mathrm{U}\left(\mathrm{kW} / \mathrm{m}^{2} \mathrm{~K}\right)$ & $\mathrm{R} \mathrm{R}_{\mathrm{f}}\left(\mathrm{m}^{2} \mathrm{~K} / \mathrm{kW}\right)$ \\
\hline 89.30 & 57.6 & 83.91 & 70.68 & 19.40 & 81.97 \\
65.30 & 32.27 & 72.31 & 50.02 & 71.62 & 71.42 \\
87.25 & 48.96 & 91.51 & 45.75 & 66.53 \\
85.20 & 35.10 & 90.43 & 51.15 & 43.60 \\
88.27 & 48.6 & 85.75 & & 65.05 & 72.61 \\
\hline
\end{tabular}


Table 6. Percentage (\%) performance of the heating elements at off-design point: scenario two.

\begin{tabular}{cccccc}
\hline Capacity Ratio (CR) & Effectiveness $(\varepsilon)$ & LMTD & Heat Transfer Rate Q $(\mathrm{KW})$ & $\mathrm{U}\left(\mathrm{kW} / \mathrm{m}^{2} \mathrm{~K}\right)$ & $\mathrm{R}_{\mathrm{f}}\left(\mathrm{m}^{2} \mathrm{~K} / \mathrm{kW}\right)$ \\
\hline 90.14 & 75.00 & 0.05 & 20.04 & 83.65 & 63.52 \\
92.32 & 71.82 & 23.85 & 45.40 & 67.91 & 34.55 \\
97.82 & 95.00 & 16.51 & 50.17 & 72.49 & 31.91 \\
96.50 & 91.82 & 0.04 & 41.89 & 51.09 & 52.06 \\
95.30 & 89.09 & 15.79 & 69.82 & 78.60 & 12.69 \\
\hline
\end{tabular}

Table 7. Percentage (\%) performance of the heating element at off-design: scenario three.

\begin{tabular}{cccccc}
\hline Capacity Ratio (CR) & Effectiveness $(\varepsilon)$ & LMTD & Heat Transfer Rate Q $(\mathrm{KW})$ & $\mathrm{U}\left(\mathrm{kW} / \mathrm{m}^{2} \mathrm{~K}\right)$ & $\mathrm{R}_{\mathrm{f}}\left(\mathrm{m}^{2} \mathrm{~K} / \mathrm{kW}\right)$ \\
\hline 93.88 & 73.56 & 8.84 & 37.33 & 27.71 & 1.39 \\
93.52 & 72.19 & 25.32 & 44.43 & 33.57 & 13.69 \\
93.47 & 71.87 & 35.43 & 46.67 & 17.70 & 11.44 \\
92.86 & 74.03 & 13.42 & 59.43 & 33.23 & 13.82 \\
94.39 & 77.34 & 42.32 & 44.79 & 6.26 & 9.58 \\
\hline
\end{tabular}

performance of the system at the three scenarios. The values of the capacity ratio, effectiveness, LMTD, heat duty and overall heat transfer coefficient at difference temperature gradient across the stream are presented.

Table 5 shows the result of a percentage performance of the indicators. The capacity ratio represents an average of $83.06 \%$ of the design value. This represents a deviation of about $16.94 \%$ which is practically negligible due to the specific heat capacity deviation and heat losses across the heating elements. The effectiveness gave an average of $45 \%$ which is quite below expectation. This is basically expressed in the increase in fouling by about $55 \%$. Fouling and heat loss are major elements that deteriorate the performance trend of heat exchanging systems. The LMTD shows an $84.8 \%$ performance on average, while the heat transfer rate shows $57.8 \%$ performance. The overall heat transfer coefficient gave an average of $68.06 \%$ performance on the design value. The performance based on the heat transfer coefficient is traceable to the temperature gradient and heat transfer area. Increase in the fouling as earlier explained minimized the active area for heat to be transferred.

Table 6 shows the off-design performance results. The analysis is aimed at theoretically minimizes the energy losses. The Table shows that the capacity ratio has improved to about $94 \%$ of the design value and the effectiveness to $85.5 \%$, while the heat duty performance is $88 \%$ of the design value. This represents a good improvement on the system performance. It also revealed that the overall heat transfer performance has improved to $71 \%$. The improvement is reflected in the drop of the fouling factor to about $38.9 \%$. Table 7 indicated a further drop in the fouling factor by an average of $9.9 \%$. This reflected on the overall heat transfer performance to $76.4 \%$ of the design value.

A Comparative analysis of the three performance scenarios shows that the best performance in capacity ratio, effectiveness and LMTD occurs at the off-design analysis at lower temperature on the hot stream. Although in the third scenario, the overall heat transfer shows its best performance.

\section{Conclusion}

This research evaluates three performance scenario of the heat exchanger, and revealed its performance trend and deviation from the design values. The elements of fouling and heat loss degrade the system performance such as expressed in the capacity ratio, effectiveness and the overall heat transfer coefficient. The overall system performance depends greatly on the temperature difference across the stream which is a function of the heat transfer area and material. The LMTD is a performance indicator that expresses the heat transfer based on its value, which is temperature dependent. This evaluation therefore provides the information on the efficiency and help to check deterioration that may result over time if maintenance measures are not sustained. The deviation may gradually increase over time, and proactive measure and condition monitoring is paramount to maintain or 
minimize these deviations to negligible percentage. The off-design scenarios predict the performance of the heat exchanger when certain parameters are optimized as well as minimization of fouling and energy losses. The optimized parameters serve as the objective function that is dependable on the minimized variables and other environmental constraints. This research provides a good technical approach to evaluate the thermal performance of the heat exchanger used in process engineering.

\section{References}

[1] Rajput, R.K. (2006) Heat and Mass Transfer. 3rd Edition, S.Chand and Company Limited, Ram Nagar, New Delhi, 569-648.

[2] Aghareed, M.T., El-Rifai, M.A., Tawil, Y.A. and Abdel-Monen, R.M. (1991) A New Dynamic Model for Shell and Tube Heat Exchanger. Energy Conversation Management, 32, 439-446. http://dx.doi.org/10.1016/0196-8904(91)90005-4

[3] Rao, B.P., Kumar, P.K. and Das, S.K. (2002) Effect of Flow Distribution to the Channels on the Thermal Performance of a Plate Heat Exchanger. Chemical Engineering and Processing: Process Intensification, 41, 49-58. http://dx.doi.org/10.1016/S0255-2701(01)00105-2

[4] Pussey, H.C. (2007) Turbo Machinery Condition Monitoring and Failure Prognosis, Shock and Vibration Information Analysis, Centre/Hi-Test Laboratories. Proceedings of Institute of Vibration, Winchester, VA, 210.

[5] Kakac, S. and Liu, H. (2002) Heat Exchanger Selection Rating and Thermal Design. 2nd Edition, CRC Press, Boca Raton.

[6] Lebele-Alawa, B.T. and Innocent, A.O. (2014) Influence of Fouling on Heat Exchanger Effectiveness in a Polyethylene Plant. Energy and Power, 4, 29-34.

[7] Genic, S.B., Jacimovic, B.M., Mandic, D. and Petrovic, D. (2012) Experimental Determination of Fouling Factor on Plate Heat Exchangers in District Heating Systems. Energy and Building, 50, 204-211. http://dx.doi.org/10.1016/j.enbuild.2012.03.039

[8] Zimparov, D. (2006) Performance Evaluation of Tube-in-Tube Heat Exchanger with Heat Transfer Enhancement in the Annulus. Original Scientific Paper UDC:66.045.1:519.876.5. http://dx.doi.org/10.2298/tsci0601045z

[9] Hewitt, G.H., Shires, G.L. and Bott, T.R. (1994) Process Heat Transfer. CRC Press Inc, Florida.

[10] Bell, D.R. (2003) The Hidden Cost of Downtime: Strategies for Improving Return Assets. Smant Signal Co., Illinois, $1-4$.

[11] Lunsford, K.M. (2006) Increasing Heat Exchanger Performance. Proceedings of Bryon Research and Engineering Incorporated, Bryan, TX, 1-13.

[12] Gulley, D. (1996) Trouble Shooting Shell-Tube Heat Exchanger: Hydrocarbon Processing. Journal of Heat Transfer, 75, 91-98.

[13] Ogbonnaya, E.A. (2010) Maintenance Optimization of a Marine Heat Exchanger Subject to Fouling. Journal of Energy Trend in Engineering and Applied Science, 1, 161-168.

[14] Coreneliseen, R.L. (1997) Thermodynamic and Sustainable Development: The Use of Exergy Analysis and the Reduction of Irreversibility. Technical Paper, International Energy, Life Cycle Assessment and Sustainability.

[15] Chii, D.H. (2009) Performance Improvement in a Concentric Circular Heat Exchanger with External Recycled under Uniform Wall Fluxes. Journal of Science and Engineering, 12, 231-238. 


\section{Nomenclature}

$\begin{array}{ll}A & \text { Heat Transfer Area }\left(\mathrm{m}^{2}\right) \\ C_{p h} & \text { Specific Heat Capacity of Hot Fluid } \\ C_{p c} & \text { Specific Heat Capacity of Cold Fluid } \\ R_{f} & \text { Fouling Factor } \\ m_{c} & \text { Mass Flow Rate of Cold Fluid }(\mathrm{kg} / \mathrm{h}) \\ m_{h} & \text { Mass Flow Rate of Hot Fluid }(\mathrm{kg} / \mathrm{h}) \\ Q_{h} & \text { Heat Duty of Hot Fluid }(\mathrm{kW}) \\ Q_{c} & \text { Heat Duty of Cold Fluid }(\mathrm{kW}) \\ C R & \text { Capacity Ratio } \\ \varepsilon & \text { Effectiveness } \\ t_{1} \& t_{2} & \text { Wall Temperatures }{ }^{\circ} \mathrm{C} \\ t_{h 1} & \text { Inlet Temperature of Hot Fluid }{ }^{\circ} \mathrm{C} \\ t_{h 2} & \text { Outlet Temperature of hot Fluid }{ }^{\circ} \mathrm{C} \\ t_{c 1} & \text { Inlet Temperature of Cold Fluid }{ }^{\circ} \mathrm{C} \\ t_{c} & \text { Out Temperature of Cold Fluid }{ }^{\circ} \mathrm{C} \\ \Delta t_{c} & \text { Change in Cold Fluid Temperature } \\ \Delta t_{h} & \text { Change in Hot Fluid Temperature } \\ U & \text { Overall Heat Transfer Coefficient } \\ U_{c l e a n} & \text { Overall Heat Transfer Coefficient from Design }\left(\mathrm{kW} / \mathrm{m}^{2} \mathrm{~K}\right) \\ U_{\text {dirty }} & \text { Overall Heat Transfer Coefficient from Operation }\left(\mathrm{kW} / \mathrm{m}^{2} \mathrm{~K}\right) \\ \mathrm{LMTD} & \text { Log Mean Temperature Difference } \\ \Delta P_{t} & \text { Pressure Loss Coefficient } \\ R_{s i} & \text { Thermal Resistance to Scale Formation on the Inside Surface } \\ R_{s o} & \text { Thermal Resistance to Scale Formation on the Outside Surface } \\ & \end{array}$

\section{Warmly welcome your paper submission to OALib Journal!}

- Publication on a daily basis

- 9 subject areas of science, technology and medicine

- Fair and rigorous peer-review system

- Fast publication process

- Article promotion in various social networking sites (LinkedIn, Facebook, Twitter, etc.)

- Widely-targeted and multidisciplinary audience to read your research

Submit Your Paper Online: Click Here to Submit Contact Us: service@oalib.com 